www.jmscr.igmpublication.org

Impact Factor 5.84

Index Copernicus Value: 83.27

ISSN (e)-2347-176x ISSN (p) 2455-0450

crossref DOI: _https://dx.doi.org/10.18535/jmscr/v5i3.49

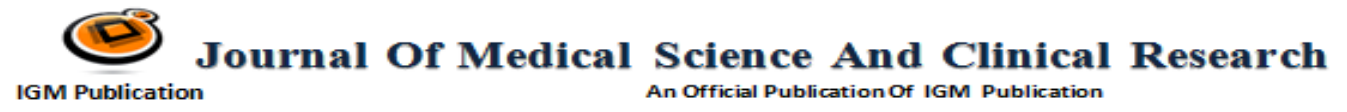

\title{
Study of Bacterial Isolates in Puerperal Sepsis \& its Antibiotic Sensitivity
} Pattern

\author{
Authors \\ Dr Kishor V. Ingole ${ }^{1}$, Dr Preeti P. Shendre ${ }^{2}$ \\ ${ }^{1}$ Professor \& Head, Department of Microbiology, Dr V. M. Govt. Medical College, Solapur \\ ${ }^{2}$ PG Student, Department of Microbiology Shri. Vasantrao Naik Government Medical College, Yavatmal \\ Maharashtra- 445001 INDIA
}

\begin{abstract}
:
Aims \& Objective: 1) To find out common organisms causing puerperal sepsis.

2) To find out it's antibiotic sensitivity pattern.

3) To find out associated risk factors for puerperal sepsis.

Materials \& Methods: This Cross Sectional study was carried out for a period of 2 years from December 2014 to September 2016. The clinically suspected cases of puerperal sepsis were included in this study. Endocervical swab or secretion and blood from each case were collected following standard procedure for microscopic examination and isolation of bacteria with antimicrobial susceptibility. The isolates were identified on the basis of colony morphology, from colony Gram staining and appropriate biochemical tests. The isolates were identified per standard biochemical testing and antibiotic sensitivity testing was done as per CLSI guidelines.

Observation \& Result: Out of 67 women admitted in present study, majority 54 (80.59\%) were between 20 and 29 years of age. Majority of them were uniparous (50.74\%). 46 showed bacterial growth rests of the samples were sterile. Gram negative organisms were isolated in 31 cases (67.39\%) while Gram positive organisms in 15 cases (32.60\%). Klebsiella was the most frequent isolate 13 (28.26\%) followed by Staph. aureus 10 (21.73\%). In the present study, out of 67 cases studied, bacteremia was present in 46 (68.65\%) cases. Present study shows predominance of Gram negative bacilli (67.39\%) with $32.60 \%$ isolates being Gram positive cocci.

Conclusion: In view of the changing spectrum of the causative agents of puerperal sepsis and their antibiotic sensitivity patterns from time to time and from one hospital to another, a positive blood culture and the antibiotic susceptibility testing of the isolates are the best guide in choosing the appropriate antimicrobial therapy in treating puerperal sepsis.

Keywords: Purperal sepsis, antibiotic sensitivity pattern, blood culture.
\end{abstract}

\section{Introduction}

Motherhood is a distinct bio-psychosocial process that transforms and broadens the role of a woman into that of a mother. Childbirth is a life changing event as wonderful and joyful experience as it for many, it can also be a difficult period, bringing with it new problem, which have potential to be life threatening. Puerperal pyrexia and sepsis are among the leading causes of preventable maternal morbidity and mortality not only in developing countries but in developed countries as well ${ }^{(1)}$. WHO has defined puerperal sepsis as "a genital 
tract infection occurring between rupture of membranes and $42^{\text {nd }}$ day postpartum, coinciding with fever $\&$ one of the following like pelvic pain, abnormal vaginal discharge, abnormal odour or discharge, or a delay in reduction of uterine size must also be present."

Puerperal sepsis occurs in $1-8 \%$ of all deliveries. Fifteen percent of maternal death is attributed to puerperal sepsis in India \& $16.4 \%$ worldwide. Maternal mortality ratio is a sensitive indicator of health status of women ${ }^{(2)} 35 \%$ of maternal morbidity is due to puerperal sepsis in India. Puerperal sepsis contributes to a lot of maternal morbidity, more so in rural women. This incidence is 5-10 times higher when a woman is delivered by cesareans section. Study of common organisms causing puerperal sepsis and its antibiotic sensitivity pattern will help to start prompt antibiotics treatment till culture report comes.

The organisms which cause it include Staph. aureus, Strep. pyogenes, Coliform bacteria ${ }^{(3)}$. There are very few studies particularly on bacterial etiology of puerperal sepsis. It is known that bacterial pattern with their antimicrobial susceptibility is a dynamic and changing phenomenon and surveillance of this event is needed in every healthcare setting. The study was aimed to determine causative organisms and antibiotic susceptibility of the isolates.

Puerperal sepsis is a systemic inflammatory response to infection in genital organs which is manifested by fever, tachycardia, local vaginal discharge, tachypnoea and hypothermia. Causes of puerperal sepsis is attributed to no or improper use of aseptic technique during delivery or in immunocompromised mothers ${ }^{(4)}$. Predisposing factors leading to puerperal sepsis includes primiparity, prolonged labour, anaemia multiple vaginal examinations during labour and post partum period. beside this endometritis, wound infection, mastitis, urinary tract infection and septic thrombophlebitis are the chief causes of puerperal sepsis ${ }^{(5)}$.

\section{Aims \& Objective}

1. To find out common organisms causing puerperal sepsis.

2. To find out it's antibiotic sensitivity pattern.

3. To find out associated risk factors for puerperal sepsis.

\section{Materials and Methods}

This Cross Sectional study was carried out in the Department of Microbiology, Shri V. N. Medical College, Yavatmal for a period of 2 years from December 2014 to September 2016. The clinically suspected cases of puerperal sepsis were included in this study ${ }^{(6)}$. Patients with similar sign and symptoms but diagnosed as having other diseases e.g. UTI, Malaria, Typhoid, carcinoma of the cervix, cervical polyp, ulcerated uterine prolapse and vaginosis \& also the patients with history of taking prior antibiotic treatment within 7 days were excluded from the study. All relevant history, clinical findings and laboratory records of every case was systematically recorded in a pre designed data sheet for subsequent analysis by computer programme SPSS version 12.0. Verbal consent was taken from every patient before sample collection and the purpose of the procedure was explained clearly.

Endocervical swab or secretion and blood from each case were collected following standard procedure for microscopic examination and isolation of bacteria with antimicrobial susceptibility. Specimens were collected carefully to avoid normal resident flora. One aliquot of collected specimen was immediately inoculated in Blood agar media at bed side for anaerobic culture. The rest of the specimen was transferred to the Department of Microbiology for further investigations. Wet Film and Smear were prepared from each of the cervical sample. Prepared Smear was stained by Gram staining. Wet Film and the stained smears were searched for observing morphology of relevant organisms and number of pus cell ${ }^{(7)}$. Cervical swablsecretion was inoculated into two plates of Blood agar, One Mac Con Keys agar, One Nutrient agar and One Mannitol salt 
agar medium. One Blood agar, Mac Con Key,s agar, Nutrient agar and Mannitol salt agar medium was incubated at $37^{\circ} \mathrm{C}$ for 24 hours aerobically. Another Blood agar plate was incubated anaerobically at $37^{0} \mathrm{C}$ for $48 \mathrm{hrs} .{ }^{(8)}$. The Gas Pak TM EZ Anaerobe Container system was used for anaerobic culture (Becton, Dickinson and Company. Sparks, USA). The jar was incubated at 370C for 48 hours.

From each patient, $10 \mathrm{ml}$ of blood was collected in Brain Heart Infusion Agar-Brain Heart Infusion Broth (BHIA-BHIB). Blood culture bottles were observed daily for signs of growth like turbidity, colonies over solid slant portion and subcultured onto solid media like blood agar and Mac Conkeys agar and evaluated after 24 hours, 48 hours and maximum upto 7 days before declaring it as negative. Blood culture bottles were incubated at $37^{\circ} \mathrm{C}$ aerobically within an hour after collection of blood at bed side. Blood culture bottles were examined macroscopically for growth in the morning and afternoon on the 1st day of incubation and in the morning of each day thereafter. Culture that appeared as per hazy appearance of the broth were picked up and Gram stain was done ${ }^{(9)}$. Subculture were done on Blood agar, Nutrient agar and Mac Conkey agar media and incubated at $37^{\circ} \mathrm{C}$ for 48 hours aerobically. Bottle that appeared macroscopically negative were examined with Gram stain on the 1st, 4th and 7th day of incubation and blind subculture were done on the 1st and 4th days to a Blood agar. Sub cultured plates were held for two days before they were discarded as negative. The Blood culture bottles were kept on incubation for 1 weeks and were discarded when there was no growth $^{(7,9)}$. Isolation of bacteria from the collected specimens were done by inoculating the samples into Nutrient agar, Blood agar, Mac Conkey agar, Trypticase soya broth and Thioglycollate broth media within earliest possible time (less than one hour) after collection. Inoculated Petri dishes were then incubated at $37^{\circ} \mathrm{C}$ for 24 48 hours aerobically and anaerobically using gas pack and anaerobic jar. The isolates were identified on the basis of colony morphology, from colony Gram staining and appropriate biochemical tests. The isolates were identified per standard biochemical testing and antibiotic sensitivity testing was done as per CLSI guidelines.

\section{Observation \& Result}

Table 1: shows age and parity of patients. Majority of women belongs to 20-29 years of age group.

Table 1: Age and parity.

\begin{tabular}{|c|c|c|}
\hline Age (years) & parity & Number of cases \\
\hline$<19$ & 1 & 6 \\
\hline $20-29$ & 1 & 28 \\
\hline & 2 & 17 \\
\hline & $3-4$ & 9 \\
\hline $30-39$ & 2 & 3 \\
\hline & $3-4$ & 4 \\
\hline TOTAL & & 67 \\
\hline
\end{tabular}

Table 2: Place and type of delivery.

\begin{tabular}{|l|c|c|}
\hline Place & Type of delivery & $\begin{array}{c}\text { Number of } \\
\text { cases }\end{array}$ \\
\hline Study hospital & Normal delivery & 17 \\
\hline & Institutional V D & 6 \\
\hline & Caesarean section & 2 \\
\hline Other hospitals & Normal delivery & 13 \\
\hline & Institutional V D & 5 \\
\hline & Caesarean section & 3 \\
\hline Home & Normal delivery & 21 \\
\hline Total & & 67 \\
\hline
\end{tabular}

VD-Vaginal Delivery

Table 3: Shows various isolates. Sixty seven patients from Obstetric department were evaluated over a period of two years. Of them, 46 showed bacterial growth rests of the samples were sterile. Gram negative organisms were isolated in 31 cases $(67.39 \%)$ while Gram positive organisms in 15 cases $(32.60 \%)$. Klebsiella was the most frequent isolate $13(28.26 \%)$ followed by Staph. aureus $10(21.73 \%)$.

Table 3: Isolates in blood culture.

\begin{tabular}{|l|c|c|}
\hline Organisms isolated & Number & Percentage \\
\hline Kleb. aerogenes & 13 & $28.26 \%$ \\
\hline Staph. aureus & 10 & $21.73 \%$ \\
\hline Pseudo. aeruginosa & 9 & $19.56 \%$ \\
\hline Proteus & 5 & $10.86 \%$ \\
\hline E. coli & 4 & $8.69 \%$ \\
\hline Strept. pyogenes & 3 & $6.52 \%$ \\
\hline Staph. albus & 2 & $4.34 \%$ \\
\hline Total & 46 & $68.65 \%$ \\
\hline
\end{tabular}


Table 4 shows antimicrobial sensitivity pattern of isolates. Most of the organisms are resistant to ampicillin, penicillin and amikacin.

\begin{tabular}{|l|c|c|c|c|c|c|c|c|}
\hline $\begin{array}{l}\text { Isolates } \\
\text { Antibiotics }\end{array}$ & $\begin{array}{c}\text { K.aerogene } \\
\mathrm{s} \\
\mathrm{n}=13)\end{array}$ & $\begin{array}{c}\text { Staph. } \\
\text { aureus } \\
(\mathrm{n}=10)\end{array}$ & $\begin{array}{c}\text { Pseudo. } \\
\text { aeruginosa } \\
(\mathrm{n}=9)\end{array}$ & $\begin{array}{c}\text { Proteus } \\
\text { species } \\
(\mathrm{n}=5)\end{array}$ & $\begin{array}{c}\text { E. coli } \\
(\mathrm{n}=4)\end{array}$ & $\begin{array}{c}\text { Strep. } \\
\text { pyogenes } \\
(\mathrm{n}=3)\end{array}$ & $\begin{array}{c}\text { Staph. } \\
\text { albus } \\
(\mathrm{n}=2)\end{array}$ & Total $(\mathrm{n}=46)$ \\
\hline Ampicillin & $4(30.76)$ & $1(10)$ & $5(55.55)$ & $1(20)$ & $0(0)$ & $1(33.33)$ & $1(50)$ & $13(28.26)$ \\
\hline Gentamicin & $11(84.61)$ & $8(80)$ & $6(66.66)$ & $3(60)$ & $2(50)$ & $2(66.66)$ & $1(50)$ & $33(71.73)$ \\
\hline Cotrimoxazole & $2(15.38)$ & $2(20)$ & $1(11.11)$ & $1(20)$ & $1(25)$ & $1(33.33)$ & $0(0)$ & $8(17.39)$ \\
\hline Ciprofloxacin & $12(92.30)$ & $7(70)$ & $8(88.88)$ & $5(100)$ & $3(75)$ & $3(100)$ & $2(100)$ & $38(82.60)$ \\
\hline Cephalexin & $4(30.76)$ & $10(100)$ & $5(55.55)$ & $2(40)$ & $1(25)$ & $3(100)$ & $2(100)$ & $23(50)$ \\
\hline Norfloxacin & $9(69.23)$ & $7(70)$ & $4(44.44)$ & $1(20)$ & $2(50)$ & $0(0)$ & $0(0)$ & $23(50)$ \\
\hline Amikacin & $8(61.53)$ & $7(70)$ & $5(55.55)$ & $4(80)$ & $2(50)$ & $2(66.66)$ & $1(50)$ & $29(63.04)$ \\
\hline Penicillin & $1(7.69)$ & $2(20)$ & $2(11.11)$ & $\underline{0(0)}$ & $\underline{1(25)}$ & $\underline{2(66.66)}$ & $\underline{1(50)}$ & $\underline{9(19.56)}$ \\
\hline Erythromycin & $2(15.38)$ & $1(20)$ & $1(11.11)$ & $0(0)$ & $0(0)$ & $2(66.66)$ & $2(100)$ & $8(17.39)$ \\
\hline Polymyxin B & - & - & $7(77.77)$ & $1(20)$ & - & - & - & $8(17.39)$ \\
\hline Carbenicillin & & & $6(66.66)$ & $1(20)$ & & & & 7 \\
\hline
\end{tabular}

\section{Discussion}

Post partum morbidity continues to be major health issues which need to be looked into critically not only for curative but preventive and promotive health. It is being believed that in developing countries $65 \%$ of all women have some form of antenatal care and 53\% intranatal care, only $30 \%$ receive postpartum care. A big proportion of Indian women still deliver at home with or without any prenatal and intranatal care. They are malnourished, anemic and remain prone to postpartum complications.

Out of all the women admitted in present study, six $(8.95 \%)$ were teenagers, $54 \quad(80.59 \%)$ between 20 and 29 years of age and $7(10.44 \%)$ between 30 and 39 years. Majority of the women came from lower socioeconomic class. Majority of them were uniparous $(50.74 \%), 29.85 \%$ belonged to parity two, $19.40 \%$ to parity 3 or 4 (Table 1). Of the 67 women, 21(31.34\%) has delivered at home, $21(31.34 \%)$ at other hospitals or private maternity homes and $25(37.31 \%)$ at the study hospital (Table 2). It is important to understand the bacteriology of puerperal sepsis. Enhanced detection of blood stream infections needs to be a national priority. Blood culture is the essential investigation for the management of sepsis. In the present study, out of 67 cases studied, bacteremia was present in $46(68.65 \%)$ cases. The ratio of Gram positive to Gram negative organism was (2.06: 1). Present study shows predominance of Gram negative bacilli
(67.39\%) with $32.60 \%$ isolates being Gram positive cocci. Similar findings reported by another study which showed isolation of Gram negative organism as $60 \%$ and Gram positive cocci as $40 \%$ from cases of puerperal sepsis ${ }^{(10)}$.

Distribution of bacteria as the cause of puerperal sepsis observed in the present study was in contrast to the other studies. They showed predominance of Gram positive cocci (78\%) with $8 \%$ isolates being Gram negative bacteria ${ }^{(11)}$. Klebsiella and Staph. aureus were the major isolates in the present study. Other studies from India reported E.coli as the predominant pathogens followed by Staph. aureus and Klebsiella $^{(12,13)} \quad$ Whereas Venugopal and Bhaskaran and Omu and Ajabor reported E. coli as the predominant pathogen in puerperal sepsis ${ }^{(14,15)}$. Other organisms isolated in our study were Pseudomonas aeruginosa, Proteus, E. coli, Streptococcus pyogenes and coagulase negative Staphylococci in the descending order of their frequency. Other study found E. coli as the predominant bacteria $(50 \%)$ followed by Staphylococcus species (30\%) and Streptococcus species $(20 \%)^{(16)}$. Distribution of E. coli, Staphylococcus species and Streptococcus species in another study done in USA was reported to be $36 \%, 28 \%$ and $21 \%$ respectively ${ }^{(17)}$. The most common bacteria were Staph. epidermidis, E. coli, Enterococci and streptococci ${ }^{(18)}$.The frequency of puerperal infection due to Group A beta hemolytic Streptococci has decreased greatly in the $21 \mathrm{st}$ 
century and now rarely caused maternal death. In the 18th and 19th centuries puerperal infection was a serious life threatening condition ${ }^{(19)}$. In the present study, antimicrobial susceptibility of different bacterial isolates was seen. Kleb. aerogenes shows sensitivity to ciprofloxacin $(92.30 \%)$ and gentamicin (84.61\%), Pseudo. aeruginosa shows sensitivity to ciprofloxacin $(88.88 \%)$. Majority of the isolates of Proteus were sensitive to ciprofloxacin (100\%) and Amikacin (80\%). E. coli shows sensitivity to ciprofloxacin (75\%). Staph aureus shows sensitivity to cephalexin (100\%), gentamicin $(80 \%)$ and ciprofloxacin (70\%). Strep. Pyogenes was $100 \%$ sensitive to cephalexin and ciprofloxacin. Others reported that majority of different Gram positive cocci shows sensitivity to cephalosporin. Another study from Nepal also observed that $100 \%$ strains of Gram positive cocciwere sensitive to cephalexin $^{(20)}$. Finding of the two studies mentioned above were well consistent with results of the present study. In a study by Modi et al E. coli and other Gram negative bacteria showed $100 \%$ sensitivity to gentamicin which was not similar to our study ${ }^{(21)}$. Sensitivity to ciprofloxacin among different bacteria as found in the present study was similar to Marten et al. ${ }^{(22)}$.

\section{Conclusion}

Klebsiella and Staph. aureus were the major isolates in puerperal sepsis. Kleb. aerogenes shows sensitivity to ciprofloxacin $(92.30 \%)$ and gentamicin. Staph. aureus shows sensitivity to cephalexin (100\%), gentamicin $(80 \%)$ and ciprofloxacin $(70 \%)$.Blood culture is still the 'Gold Standard' for the diagnosis of puerperal sepsis and should be done in all cases of suspected septicemia. In view of the changing spectrum of the causative agents of puerperal sepsis and their antibiotic sensitivity patterns from time to time and from one hospital to another, a positive blood culture and the antibiotic susceptibility testing of the isolates are the best guide in choosing the appropriate antimicrobial therapy in treating puerperal sepsis.

\section{References}

1. Maharaj D. Puerperal pyrexia; a review. Part II. Obstet Gynecol Surv. 2007;62 (6):400-6.

2. Kumar R, Sharma AK, Barik S, Kumar V. Maternal mortality inquiry in a rural community of north India. Int J Gynaecol Obstet. 1989;29:313-9.

3. Daftary SN, Chakravarti S. Obstetric shock. Manual of Obstetric, 2nd Edition; Elsevier publisher. 2005.

4. Abouzahr C ,Aahman E.,Guidotti R. Puerperal sepsis and other puerperal infections. Health organization and the world bank.1998;pg-191-217

5. V.Ruthbeneth.LindaK.Brown.Textbook of Myles. Third edition 2001.pg-589

6. WHO, 2004; Basu, 2003

7. Duguid JP, MacKie and McCartney Practical Medical Microbiology. Collee JG, Duguid JP, Fraser AG, Marmion BP (editors).13th ed. Churchill. Livingstone, New York.1989; 2:360-396.

8. Cheesbrough M. District laboratory practice in tropical countries, vol 2, Low price edition, University of Cambridge, United Kingdom 2000.

9. Blazevic DJ, Stemper JE \& Master JM. Comparison of macroscopic examination .Routine Gram stains and Routine subculture in the initial detection of positive blood culture. Applied Microbial. 1974; 27: 37-539.

10. Naheed T, Akbar N. Patients with postpartum complications admitted in a Medical ward of Mayo Hospital, Lahore, Pakistan. J Med Sc. 2002;18(2):126-30.

11. Chaisilwatana P, Roongpisuthipong A. Causative organisms in puerperal sepsis. $\mathbf{J}$ Med Assoc Th. 1991;74(3):159-61.

12. Rao K, Ramji S, Thirupuram S, Prakash K. Clinical and bacteriological study of normal and inflamed neonatal conjunctiva. Indian Pediatr. 1992;29:161-5.

13. Kerur BM, Batt BV, Harish BN, Habeebullah S, Kumar CU. Maternal 
genital bacteria and surface colonization in early neonatal sepsis. Indian $\mathbf{J}$ Pediatr. 2006;73(1):29-32.

14. Venugopal MS, Bhaskaran CS. Puerperal and postabortal sepsis (a bacteriological study). J ObstetGynaecol India. 1968;18 (1):70-8.

15. Omu AE, Ajabor LN.Contribution of endotoxic shock to gynecological and maternal morbidity and mortality.J Obstet Gynaecol East Cent Africa.1983;2(1):41-5.

16. Baker JN. Study of cases of puerperal pyrexia in a tertiary level hospital. [Dissertation] Dhaka, Bangladesh: Sir Salimullah Medical College and Mitford hospital. 2005:34.

17. Decherny AH, Nathan L. Postpartum hemorrhage and the abnormal puerperium In: Current Obstetrics and Gynecologic diagnosis and treatment, 9th ed. UK: Prentice Hall International Inc. 2003:531-52.

18. Gerstner G, Leodolter S, Rotter M. Endometrial bacteriology in puerperal infections. Z. GeburtshilfePerinatol. 1981;185 (5):276-9.

19. Newsom Sw. Pioneers in infection control. Ignaz Philip Semmelweis. J Hosp Infect. 1993;23:175-87.

20. Pokharel MS. Study on antibiotic sensitivity pattern of bacterial flora in cases of pre-labor rupture of membranes. [Dissertation] Kathmandu, Nepal: Tribhuvan University. 2004:108.

21. Modi S, Kar J, Gupta.Puerperalsepsis.Cur MedPract.1986;30(12):301-6.

22. Martens MG, Faro S, Maccato M, Riddlw G, Hammill HA. Susceptibility of female pelvic pathogens to oral antibiotic agents in patients who develop postpartum Endometritis. AM J Obstet Gynecol. 1991;164:1383-6. 